\title{
LAPAROSCOPIC NEPHROPEXY: TREATMENT OUTCOME AND QUALITY OF LIFE
}

\author{
Deyan Anakievski ${ }^{1,2}$, Alexander Hinev ${ }^{1,2}$, Rostislav Marinov ${ }^{2}$, Inna Gocheva ${ }^{2}$ \\ ${ }^{1}$ Department of Surgery, Faculty of Medicine, Medical University of Varna \\ ${ }^{2}$ Clinic of Urology, St. Marina University Hospital
}

\begin{abstract}
INTRODUCTION: Surgical treatment of nephroptosis is rarely performed nowadays and is done only in symptomatic patients. Here we present the results of our laparoscopic nephropexy in patients with symptomatic nephroptosis.

MATERIALS AND METHODS: For a period from March 2014 to March 2015, a total of 8 women at an average age of 54 years were operated on in our clinic. Four of the patients were with nephroptosis of the left kidney, three of the right one and one had bilateral nephroptosis. Most of the patients complained of pain and discomfort in active movement, only one individual had complaints consisting of intermittent macroscopic hematuria. One patient had been operated on in the past by a classic open method of the same kidney. Preoperatively, for all patients, intravenous urography in supine and standing position was performed. All patients were operated on trans-peritoneally through 3 ports: $1 \times 10 \mathrm{~mm}$ and $2 \times 5 \mathrm{~mm}$. The kidney was completely mobilized and kidney fat was dissected. The upper and middle pole of the kidney were fixed to musculus psoas major, using a single non-absorbable suture and intracorporeal technique for tying.

RESULT: All operations were performed with minimal blood loss, an average operating time of 45 minutes and a hospital stay of 4 days. No conversion was required in any of the cases. Postoperatively, patients were tracked and monitored by ultrasound examination. At 3 months we did IVP, which showed the correct location of the kidney. All patients remained asymptomatic for an average of 11 months after surgery.

CONCLUSION: Laparoscopic transperitoneal nephropexy is a safe and effective procedure and a promising method for correction of symptomatic nephroptosis.
\end{abstract}

Keywords: nephroptosis, nephropexy, laparoscopy, intravenous pyelog-raphy (IVP)

Address for correspondence:

Deyan Anakievski

St. Marina University Hospital

Clinic of Urology

1 Hristo Smirnenski Blvd

9010 Varna, Bulgaria

e-mail:dejan_anakievski@yahoo.com

Received: January 16, 2017

Accepted: June 27, 2017

\section{INTRODUCTION}

Nephropexy, which is supposed to be a popular surgical procedure, has been abandoned for many years. Surgical fixation or suspension of mobile kidneys was first described in 1881 by Eugene Hahn (1). Although more than 150 different surgical techniques and modifications of nephropexy have been described, there are no definitive treatments and almost all urologists have been hesitant to treat mobile 
Deyan Anakievski, Alexander Hinev, Rostislav Marinov et al.

kidney due to the high invasiveness of the available methods compared to the severity of the symptoms (2-5). The procedure requires a large incision in the skin and division of multiple muscle layers. Postoperatively, the patients usually have no pain caused by renal ptosis, but suffer from pain due to the wound or dysesthesia caused by treatment. However, there is a certain group of patients suffering from severe symptoms due to renal ptosis, although the number of such patients is very low (2). The laparoscopic procedure is ideal for nephropexy as it produces less invasiveness and minimal post-operative pain $(6,7)$. However, after the introduction of laparoscopic procedures for nephropexy by Urban in 1993 (4), this type of surgery became the first treatment of choice for nephroptosis being a minimally invasive procedure. We have described here our experience and subsequent quality of life of patients treated with laparoscopic nephropexy and discussed its indications and surgical technique.

\section{MATERIALS AND METHODS \\ Patients:}

For the period from March 2014 to March 2015 a total of 8 women at an average age of 54 years were operated on in our clinic. Four of the patients had left nephroptosis, three had right one and one had bilateral nephroptosis. Their BMI ranged from 18 to 30 , with an average of $22 \mathrm{~kg} / \mathrm{m}^{2}$. The most frequent symptom was pain in the lumbar region during active movement, when standing upright, or in some cases - a palpable mass in the lower abdomen. Moreover, one of the eight patients had a history of intermittent gross hematuria and another was operated on in the past by the classic open method of the same kidney. Although various studies were performed to determine the cause of symptoms no reason except for nephroptosis was discovered. Seven patients (86\%) had previously undergone abdominal surgery including laparoscopic cholecystectomy, hysterectomy and classic nephropexy. Preoperatively, for all patients, intravenous urography and ultrasound in supine and upright position was performed. A descent of the kidney at distance of 2 or more vertebrae was found in all patients on the IVU (Table 1).

\section{Surgical technique:}

Preoperative bowel preparation with glycerin enema and low dose of heparin was administered to
Table.1. Patient characteristics

Patient Characteristics

$\begin{array}{lc}\text { Gender } & \\ \text { Men, } \mathrm{n} & 0 \\ \text { Women, } \mathrm{n} & 8 \\ \text { Median age, yrs. (range) } & 54(32-64) \\ \text { Median BMI kg/m² (range) } & 22.65(18.14-30.08) \\ \text { ASA score, (\%) } & \\ 1 & 6(75 \%) \\ 2 & 2(25 \%) \\ 3 & 0\end{array}$

Previous abdominal or pelvic surgery, $\mathbf{n}$

Laparoscopic cholecystectomy 3

Hysterectomy 3

Open nephropexy 1

Location, $n$ (\%)

Left kidney

$4(50 \%)$

Right kidney

$3(37.5 \%)$

Bilaterally

$1(12.5 \%)$

Symptoms, n (\%)

Pain and discomfort

Macroscopic hematuria

$1(12.5 \%)$

Surgical approach

Transperitoneal

8

Extraperitoneal

0

all patients. Patients were operated on under general anesthesia and placed in a lateral position of 20 to 30 degrees with just one patient with bilateral nephroptosis on her back. All patients were operated transperitoneally. With the help of a Veress needle insufflation we created pneumoperitoneum to $14 \mathrm{~mm} / \mathrm{Hg}$ and then placed one $10-\mathrm{mm}$ port for the camera. Additional ports were placed under optical control: one 5 -mm port subcostally in the middle clavicular line and another 5-mm one in the anterior axillary line. The line of Toldt was incised between the liver and colon ascendens, the kidney was mobilized fully at all sides by blunt and sharp dissection. The kidney was fixed to the front lateral side with $2 / 0$ non-absorbable suture starting the stitching from the upper to the lower pole of the renal capsule. Each suture was passed through the renal parenchyma itself 
on the one side and the fascia of the quadratus lumborum muscle on the other side, and the knot was intracorporeally tied. In all patients we used four threads. We placed a contact drain. The skin incision was closed with absorbable sutures (8).

\section{RESULTS}

The perioperative data and the characteristics of the patients are shown in Table 2 . There were no perioperative complications that required conversion in any of the cases. All operations were performed with minimal blood loss and an average operating time of $45 \mathrm{~min}$. The oral intake of fluids and light food began at 10 hours after surgery in all patients, and parenteral analgesia was achieved with NSAIDs. The average hospital stay was 4 days. Patients returned to their daily activities on the second postoperative week, and in four weeks returned to work (Table 2). Postoperatively, the patients were tracked and monitored by ultrasound examination. At 3 months we did IVP, which showed the correct location of the kidney. All patients remained asymptomatic for an average of 11 months after surgery.

Table. 2. Operative data

\begin{tabular}{lc}
\hline \multicolumn{2}{c}{ Operative Data } \\
Median operating time, min. (range) & $45(30-75)$ \\
Median estimated blood loss, ml & 50 \\
Conversion rate, $\mathbf{n}$ & 0 \\
No. of sutures for nephropexy & 4 \\
Postoperative complications & \\
Early (up to the $30^{\text {th }}$ day), n (\%) & $1(12.5 \%)$ \\
Late (after the $30^{\text {th }}$ day), n (\%) & $1(12.5 \%)$ \\
Hospital stay, days & 4 \\
Postoperative pain, days & 3 \\
\hline \hline
\end{tabular}

\section{DISCUSSION}

Nephroptosis is a common finding in routine IVU, with an incidence of $20 \%$ in healthy patients (9). The majority of patients are asymptomatic and nephroptosis does not require treatment. However, if symptoms occur, such as pain, hematuria or recurrent urinary tract infection, medical treatment is necessary. Although some patients are treated conservatively, such as with dieting or wearing special abdominal support bandages, usually these methods are not effective. There is no consensus on when and what type of surgery is an indication for the treatment of nephroptosis. Boeminghaus (10) differentiates patients with nephroptosis into three groups: (I) ptosis without symptoms that do not require treatment; (II) patients with symptoms but no functional changes; and (III) symptomatic patients with symptoms, as well as functional and morphological changes occasionally. He recommends performing nephropexy only in the third group of patients. There are three different operational techniques, which offer high success rate:

1. fixation using the renal capsule;

2. fixation with the use of various foreign materials;

3. fixation with the use of the patient's own tissues, such as muscle or fascial flap.

All three have the same technique steps. These are the immobilization of the kidney in the possible via the cephalic retroperitoneal position, release of urine obstruction (retention) due to nephroptosis, fixation of the kidney on its axis, so that the lower pole is positioned laterally in order to avoid traction on the vascular pedicule or ureter (11). Whichever technique is used, all authors report good results with very high success rates $(12,13)$. Rassweiler et al. (14) provide an indication of laparoscopic nephropexy in patients who after completion of IVU experience a descent of the kidney with at least two vertebrae and when there is existence of two objective symptoms or an objective and a subjective symptom alone. Also, the use of extraperitoneal access offers fewer adhesions between kidney, colon and peritoneum, although many authors prefer the transperitoneal access and report that it is better than the extraperitoneal one because of the opportunity to work in a larger space and the opportunity for intracorporeal tying (6).

\section{CONCLUSION}

Laparoscopic transperitoneal nephropexy is a safe and effective procedure and a promising method for correction of symptomatic documented nephroptosis. 


\section{REFERENCES}

1. Hahn E. Die operative Behandlung der beweglichen Niere durch Fixation. Zentralbl Chir. 1881; 29: 449- 556.

2. O'Dea M, Furlow W. Nephropexy: fact or fiction? Urology 1976;8(1):9-12. doi: 10.1016/0090-4295(76)90043-1

3. Harrison LH, Glenn JF. Nephropexy. Urol. Surg. 1969; 3: 253-5.

4. Wandschneider G, Haas P, Leb G, Passath A. Indikationsstellung und Erfolgsbeurteilung der Nephropexie mit Hilfe der kombinierten Isotopenuntersuchung der Nieren. Urologe A. 1972; 3: 161-9.

5. Wandschneider G.Results and problems of nephropexy. Urologe A. 1966; 5: 129-32.

6. Hubner WA, Schramek P, Pfliiger H. Laparoscopic nephropexy. J Urol. 1994;152(4):1184-7.

7. Elashry OM, Nakada SY, McDougall EM, Clayman RV. Laparoscopic nephropexy: Washington University experience. J Urol. 1995;154(5):1655-9.

8. Matsui Y, Matsuta Y, Okubo K, Yoshimura K, Terai A, Arai Y. Laparoscopic nephropexy: treatment outcome and quality of life. Int J Urol. 2004; 11(1): $1-6$.

9. Hoenig DM, Hemal AK, Shaihav AL, Clayman RV. Nephroptosis: A 'disparaged' condition revisited. Urology. 1999; 54(4): 590-6.

10. Boeminghaus $\mathrm{H}$. Urologie. München-Grafeling: Werk Verlag; 1971.

11. Harrison LH. Nephropexy. In: Glenn JF, editor. Urologic surgery. 3rd ed. Philadelphia: J. B. Lippincott Co.; 1983. p. 253-355.

12. Fornara P, Doehn C, Jocham D. Laparoscopic nephropexy: 3-year experience. J Urol. 1997; 158(8): 1679-83.

13. McDougall EM, Afane JS, Dunn MD, Collyer WC, Clayman RV. Laparoscopic nephropexy: Longterm follow-up. Washington University experience. J Endourol. 2000; 14(3): 247-50. doi: 10.1089/ end.2000.14.247

14. Rassweiler JJ, Frede T, Recker F, Stock C, Seemann O, Alken P. Retroperitoneal laparo-scopic nephropexy. Urol Clin North Am. 2001; 28(1): 137-44. 